\title{
Heterogeneous Selection in the Market for Private Supplemental Dental Insurance \\ Evidence from Germany
}

Bauer, Jan Michael; Schiller, Jörg; Schreckenberger, Christopher

Document Version

Accepted author manuscript

Published in:

Empirical Economics

DOI:

$10.1007 / \mathrm{s} 00181-019-01632-5$

Publication date:

2020

License

Unspecified

Citation for published version (APA):

Bauer, J. M., Schiller, J., \& Schreckenberger, C. (2020). Heterogeneous Selection in the Market for Private Supplemental Dental Insurance: Evidence from Germany. Empirical Economics, 59(1), 205-231. https://doi.org/10.1007/s00181-019-01632-5

Link to publication in CBS Research Portal

\section{General rights}

Copyright and moral rights for the publications made accessible in the public portal are retained by the authors and/or other copyright owners and it is a condition of accessing publications that users recognise and abide by the legal requirements associated with these rights.

\section{Take down policy}

If you believe that this document breaches copyright please contact us (research.lib@cbs.dk) providing details, and we will remove access to the work immediately and investigate your claim.

Download date: 26. Apr. 2023
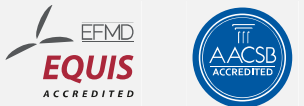


\title{
Heterogeneous Selection in the Market for Private Supplemental Dental Insurance: Evidence from Germany
}

\author{
Jan Michael Bauer, Jörg Schiller, and Christopher Schreckenberger
}

Journal article (Accepted version*)

\section{Please cite this article as:}

Bauer, J. M., Schiller, J., \& Schreckenberger, C. (2020). Heterogeneous Selection in the Market for Private Supplemental Dental Insurance: Evidence from Germany. Empirical Economics, 59(1), 205-231. https://doi.org/10.1007/s00181-019-01632-5

This is a post-peer-review, pre-copyedit version of an article published in Empirical Economics. The final authenticated version is available online at:

DOI: https://doi.org/10.1007/s00181-019-01632-5

* This version of the article has been accepted for publication and undergone full peer review but has not been through the copyediting, typesetting, pagination and proofreading process, which may lead to differences between this version and the publisher's final version AKA Version of Record. 
This is a pre-proof version and might differ from the final article published as:

Bauer, J.M., Schiller, J. \& Schreckenberger, C. Heterogeneous selection in the market for private supplemental dental

insurance: evidence from Germany. Empir Econ 59, 205-231 (2020). https://doi.org/10.1007/s00181-019-01632-5

\title{
Heterogeneous Selection in the Market for Private Supplemental Dental
}

\author{
Insurance: Evidence from Germany*
}

Jan Michael Bauer ${ }^{\mathrm{a}}$, Jörg Schiller ${ }^{\mathrm{b}}$ and Christopher Schreckenberger ${ }^{\mathrm{b}, \mathrm{c}}$

\begin{abstract}
This paper analyzes the German market for supplemental dental insurance to identify selection behavior based on individuals' private information. The rather limited underwriting by German private health insurers makes this market especially prone to selection effects. Although the standard positive correlation test does not indicate asymmetric information in this market, we conjecture that this outcome may result from sample heterogeneity when adverse and advantageous selection occur simultaneously and offset each other. Examining a large set of potential sources of selection effects, we find mainly that the holding of other supplemental health insurance policies, which is related to risk preferences, contributes to an advantageous selection in this insurance market. Our results suggest that even in the absence of a positive correlation between risk and insurance coverage, the German market for supplemental dental insurance suffers from information asymmetry, which is caused by multidimensional private information.
\end{abstract}

Keywords: Asymmetric information; advantageous selection; adverse selection; dental insurance; supplemental health insurance

JEL Classification: D82, G22, I13

\footnotetext{
* We wish to particularly thank Stefan Felder and Peter Zweifel, the University of Ulm as well as all the participants at the 41st annual EGRIE seminar, the 2015 annual meeting of the Deutscher Verein für Versicherungswissenschaft e.V. and the 3rd World Risk and Insurance Economics Congress for their helpful comments. We also thank the Bertelsmann Foundation for providing the Health Care Monitor Data in cooperation with the statutory health insurance fund Barmer GEK. We gratefully acknowledge financial support from the Deutscher Verein für Versicherungswissenschaft e.V.

${ }^{a}$ Copenhagen Business School, MSC, Frederiksberg, Denmark.

${ }^{\mathrm{b}}$ University of Hohenheim, Chair for Insurance Economics and Social Security, 70593 Stuttgart, Germany.

c Corresponding author, phone: +49 711459 22585; fax: +49 711459 23953; christopher.schreckenberger@unihohenheim.de; ORCID ID: orcid.org/0000-0003-2442-0141.
} 


\section{Introduction}

Growing health care expenditure has led to a financial burden for health care systems with universal insurance coverage. Increasing copayments and benefits restrictions in public health insurance, while offering a market for voluntary private health insurance for coverage gaps may be an option to limit public health care expenditure. In many OECD countries, especially dental care for adults is one type of benefits not at all or only partly covered by basic health insurance (Paris et al. 2010) and thus on average, 55\% of the total expenditure for dental care was paid for out-of-pocket in 2011 (OECD 2013). In the German statutory health insurance (SHI), for instance, insurance coverage for dental benefits has been incrementally reduced. This led to a tripling of SHI enrollees holding a private supplemental dental insurance (SuppDI) in addition to their SHI coverage between 2004 and 2012. Among several different supplemental health insurance (SuppHI) policies, the highest demand is on SuppDI in Germany (Grabka 2014). However, shifting coverage to voluntary private health insurance may raise equity concerns ${ }^{1}$ and carries a risk of inefficiency since asymmetric information and related selection effects may lead to a suboptimal insurance coverage at least by some individuals (Finkelstein and McGarry 2006; Rothschild and Stiglitz 1976).

The purpose of this paper is to analyze selection effects in the German market for SuppDI. This is a particularly appropriate context given that the rather limited underwriting by German private health insurers at the date of contract signing makes this market prone to selection. In a first step, we examine whether SHI enrollees have private information leading to selection effects in the aggregate. Using standard approaches for testing for asymmetric information, such as based on Chiappori and Salanié (2000), we do not find support for the basic prediction that SuppDI coverage correlates positively with the risk of needing dental care. As this finding may

\footnotetext{
${ }^{1}$ Kiil (2012) discusses equity concerns in universal health care systems with the option to buy voluntary private health insurance.
} 
result from an offsetting of adverse and advantageous selection, combined with a possible inefficient market outcome (Finkelstein and McGarry 2006), we analyze whether we identify potential sources of selection in a second step. Based on theory (de Meza and Webb 2001; Rothschild and Stiglitz 1976) and previous studies (Buchmueller et al. 2013; Fang et al. 2008; Finkelstein and McGarry 2006), we focus on risk preferences, socioeconomic characteristics and the individual's health status as potential sources. We mainly find the preference for insurance proxied by the number of other SuppHI policies except SuppDI as the main driver for advantageous selection. This is consistent with Lange, Schiller, and Steinorth (2017) who also find a positive impact of preference for insurance, proxied among others by the holding of other SuppHIs, on SuppDI coverage. In contrast to their study, which is based on data from the German Socio-Economic Panel, our data include information on dental risk enabling us to analyze selection effects. By providing evidence of heterogeneous selection despite not rejecting the null hypothesis of an insignificant coverage-risk correlation, we complement the mixed evidence on selection effects in markets for private dental insurance (e.g., Godfried et al. 2001; Srivastava et al. 2017). More generally and in line with Finkelstein and McGarry (2006), this finding suggests that a coverage-risk correlation is not a necessary condition for information asymmetry in insurance markets. Moreover, using a rich set of data, we extend the empirical literature on sources of selection. We particularly contribute to the still mixed evidence on the role of risk preferences with respect to selection behavior by identifying the holding of other insurance policies as a key source of advantageous selection in this market (e.g., Browne and Zhou-Richter 2014; Fang et al. 2008). Moreover, our findings are useful for policy implications concerning the decision to decrease coverage in the public health insurance system and to provide the option of voluntary private health insurance for coverage gaps in the public system.

The remainder of the paper proceeds as follows. Section 2 gives an overview of the German health insurance system. Section 3 then summarizes the basic theoretical effects of 
information asymmetry in insurance markets and reviews the related literature. Section 4 presents the data and empirical model. Section 5 reports and discusses the results of both the main analysis and several robustness checks. Section 6 concludes the paper.

\section{Institutional Background}

In Germany, the SHI covers nearly $90 \%$ of the population while about $10 \%$ has substitutive private health insurance (PHI). SHI has a highly uniform standard benefit package for all funds, one that is quite comprehensive compared to those in other industrialized countries (Beske et al. 2005). Due to rising health care expenditure, out-of-pocket expenses from copayments and standard benefit exclusions have recently been increasing in the SHI (Grabka 2014). In particular, a 2004 reform changed the $35 \%-50 \%$ coinsurance rate for dental prostheses to diagnosis-based fixed benefits covering $50 \%^{2}$ of the cost of standard treatment (Klingenberger and Micheelis 2005). ${ }^{3}$ Dental prostheses costs exceeding these benefits must be paid out of pocket, subjecting SHI enrollees to an increased financial risk associated with dental care.

To reduce coverage gaps in the SHI benefit package, SHI enrollees may buy SuppHI directly from private health insurers. The German market for PHI including SuppHI is imperfectly competitive (Hofmann and Browne 2013). SuppHI contracts are guaranteed renewable (Pauly et al. 1995). Among various types of SuppHI available to SHI enrollees, such as SuppDI or supplemental hospital insurance, SuppDI is the most prevalent and has the highest growth rate probably due to the 2004 reform. The proportion of SHI enrollees having SuppDI tripled after the 2004 reform from 5.6\% in 2004 to $16.6 \%$ in 2012 (Grabka 2014). The main purpose of SuppDI policies is to reduce out-of-pocket expenses for dental services, especially for

\footnotetext{
${ }^{2}$ By law, the fixed benefits can rise by $20 \%$ (30\%) if there is evidence that the insured performs regular prevention and can prove yearly dental check-ups during the last 5 (10) years before treatment.

${ }^{3}$ This rule applies to all but low-income SHI enrollees, who are eligible to receive the full cost of standard treatment. According to Barmer GEK, in 2012, about 9\% of SHI enrollees received diagnosis-based fixed benefits covering $100 \%$ of the cost of standard treatment (Rädel et al. 2014).
} 
dental prostheses. Since only the cost of standard treatment for dental prostheses is partly covered by SHI, SHI enrollees may profit even more from SuppDI policies if they prefer higher quality prostheses. Premiums for SuppDI are generally risk adjusted based on individual age at date of contract signing and gender. ${ }^{4}$ Additionally, insurers may ask applicants about past dental prostheses and advised dental or orthodontic treatment. ${ }^{5}$ Yet, the ex-ante premium differentiation for SuppDI is limited, since only few characteristics are used for pricing SuppDI policies. This may lead to selection effects from information asymmetry. ${ }^{6}$

\section{Theoretical Background and Related Literature}

The classical type of selection based on asymmetric information is adverse selection. In the standard model with adverse selection (Rothschild and Stiglitz 1976), individuals have only private information with respect to their risk type. In a separating equilibrium, high-risk individuals choose policies with higher coverage compared to low-risk individuals. In our context, this model predicts that high-risk SHI enrollees purchase SuppDI with a higher probability or - in an extreme case - are the only risk-types purchasing SuppDI, meaning that the demand of low-risk individuals is inefficiently low. The basic empirical prediction of adverse selection is that the amount of insurance coverage is positively correlated with the risk of loss controlling for all relevant characteristics used by insurers for risk-based rate making (Chiappori et al. 2006). Numerous studies have confirmed this correlation prediction in different insurance markets (see Cohen and Siegelman 2010 for a review). In a closely related paper, Godfried, Oosterbeek and van Tulder (2001) identify adverse selection in the Dutch SuppDI market after

\footnotetext{
${ }^{4}$ Since the introduction of unisex tariffs in December 2012, gender has been prohibited for determining the premiums for private health insurance policies, such as SuppDI.

${ }^{5}$ Moreover, insurers may reject applicants based on risk-related responses. For instance, some insurers reject applicants with missing teeth above a certain threshold. We will discuss this issue in our empirical model (Section 4.2) and in our robustness checks (Section 5.2) into account.

${ }^{6}$ In addition, there is no consideration of past premium payment history, meaning that the information asymmetry from a lack of ex-ante premium differentiation preserves over time.
} 
dental service exclusion from compulsory health insurance. They show that individuals with poorer dental health or more frequent past dentist visits are more likely to purchase SuppDI than individuals with better dental health or fewer past visits.

However, the prediction of a positive coverage-risk correlation is not only consistent with adverse selection, but may also arise from moral hazard (Chiappori et al. 2006). Based on theory on moral hazard (Pauly 1968; Shavell 1979), individuals with SuppDI coverage may reduce their effort into preventive dental care (ex ante moral hazard) or increase their consumption of dental care after occurrence of a dental disease (ex post moral hazard). As discussed by Cohen and Siegelman (2010) as well as Dionne (2013), different approaches have been applied in empirical studies to separate selection effects from moral hazard in insurance markets. One way is based on a natural experiment (Chiappori et al. 1998) or randomized experiment, such as in the RAND Health Insurance Experiment (Manning et al. 1987), or on exploiting other exogenous variations in the uptake of different insurance plans (e.g., Ettner 1997; Lahiri and Xing 2003). In settings with non-experimental data, another possible approach is to use simultaneous equations models or instrumental variables (e.g., Holly et al. 1998; Keane and Stavrunova 2016; Paccagnella et al. 2013; Srivastava et al. 2017).

A crucial limitation of the positive correlation test is that the correlation between insurance coverage and risk occurrence may also be negative in an imperfectly competitive insurance market like the German market for SuppDI (Chiappori and Salanié 2013). An absence of a positive correlation can be explained either by negligible information asymmetries or, for instance, by unobserved preference heterogeneity in addition to heterogeneity in risk, i.e. multidimensional private information (e.g., Cutler et al. 2008). ${ }^{7}$ Hemenway (1990) suggests that a negative risk-coverage correlation can be explained by highly risk-averse individuals that are

\footnotetext{
${ }^{7}$ Further possible explanations for the lack of a positive correlation between insurance coverage and risk occurrence, are discussed by Cohen and Siegelman (2010).
} 
more likely to buy insurance coverage and invest more in prevention so as to reduce their risk of loss. This mechanism can produce an advantageous selection in a market equilibrium as shown in the theoretical model by de Meza and Webb (2001). Based on this theory, one would expect low-risk individuals to buy SuppDI coverage more likely.

Several recent studies do find evidence for the importance of multidimensional private information in different insurance markets. Srivastava, Chen, and Harris (2017), for instance, find a positive correlation between private dental insurance in Australia and oral health as well as preventive behavior towards dental health (e.g., flossing), which is consistent with advantageous selection. In another related paper, Finkelstein and McGarry (2006) find evidence of multidimensional private information in the U.S. long-term care insurance (LTCI) market. As they do not identify a significant correlation between risk occurrence and LTCI coverage, they conclude that adverse and advantageous selection offset each other in the aggregate. Their findings indicate that a positive coverage-risk correlation is not a necessary condition for implying that an insurance market suffers from inefficiencies due to information asymmetry.

Based on de Meza and Webb (2001), risk aversion is of primary interest as a source of advantageous selection. Some studies provide evidence that factors related to risk preferences contribute to advantageous selection (e.g., Buchmueller et al. 2013; Doiron et al. 2008; Finkelstein and McGarry 2006; Schmitz 2011). Browne and Zhou-Richter (2014), for instance, find that preference for insurance measured by the holding of SuppHI policies, is a source for advantageous selection in the German LTCI market. However, insurance markets differ in whether risk preferences are an important source of advantageous selection. Fang, Keane and Silverman (2008), for instance, find that risk preferences cannot be considered as a source of advantageous selection in the U.S. Medigap insurance market. They suggest that potential sources of advantageous selection in general may be any private information about characteristics that positively correlates with insurance coverage, but negatively with the risk of loss. For 
instance, there is some evidence that socioeconomic characteristics, particularly wealth or income, contribute to advantageous selection (Buchmueller et al. 2013; Fang et al. 2008; Finkelstein and McGarry 2006).

The previous literature has provided evidence that indicates that the dominating type of selection and the role of risk preferences with respect to selection behavior is still mixed. Hence, further evidence is required to provide a better understanding of selection effects and their sources that can be used to improve market efficiency. Our paper is, to the best of our knowledge, the first study analyzing heterogeneous selection in the German market of SuppDI based on a rich data set with particularly detailed dental information. We use a comprehensive set of statistical tests to provide robust and novel insights into selection behavior in markets for SuppHI.

\section{Data and Methods}

\subsection{Data}

In our paper, we use data at the individual level from the Healthcare Monitor, a representative survey of a cross-section of the German population. ${ }^{8}$ For the present analysis, we rely exclusively on wave 19 (from 2011) because it contains very detailed information of individuals about dental health and dentist visits in addition to information on the general health status, health insurance coverage, socioeconomic characteristics and the number of physician visits. Concerning dental health, respondents were asked whether or not they have periodontitis, dental fillings, implants, dental prosthesis, caries, jaw point pain, missing teeth, toothache, and whether they wear braces or a splint against teeth grinding. With respect to health insurance, the survey collected data whether the respondents are SHI or PHI enrollees and which SuppHI policies they hold. The survey does not provide information about the premiums and the comprehensiveness of the

\footnotetext{
${ }^{8}$ The Healthcare Monitor (“Gesundheitsmonitor") is administered since 2001 by the Bertelsmann Foundation. Since 2011, the SHI fund Barmer GEK has been cooperating with the Bertelsmann Stiftung on the Healthcare Monitor.
} 
insurance policies. For this wave, a total of 2,200 individuals aged 18 to 79 were contacted by mail, of whom over $80 \%$ responded (GfK Health Care 2011). Our final sample consists of 1,781 individuals.

Table 1 shows some descriptive statistics divided by insurance status. ${ }^{9}$ PHI enrollees (column 1) tend to be older, have higher incomes, and be more predominantly male than SHI enrollees (column 2). With regard to dental health, however, we observe no major differences between the two groups. Given our focus on selection in the SuppDI market, we are particularly interested in differences between individuals with and without a SuppDI policy. Since the insurance coverage covered by SuppDI is already included in most PHI plans, we exclude PHI enrollees $(n=285)$ and only consider SHI enrollees $(n=1,496)$ in our analysis. ${ }^{10}$ Among individuals with SHI, less than one third (29\%) holds a SuppDI. The comparison between SHI with (3) and without (4) SuppDI shows that SuppDI policyholders are more likely to be married and, in line with most findings in the literature (see Kiil 2012 for a review), have a higher income. Srivastava et al. (2017), for instance, show that private dental insurance coverage is positively correlated with income in Australia. Consistent with previous findings (Browne and ZhouRichter 2014; Buchmueller et al. 2013; Lange et al. 2017), SuppDI policyholders are more likely to hold further SuppHIs.

\footnotetext{
${ }^{9}$ Note that we do not use sampling weights in Table 1 . When considering sampling weights, the descriptive statistics are quite similar for most variables (results available upon request).

${ }^{10}$ Please note that only individuals without missing values for all variables are considered in Table 1 . Thus, the number of observations in Table 1 is slightly lower.
} 
Table 1 Descriptive Statistics by Insurance

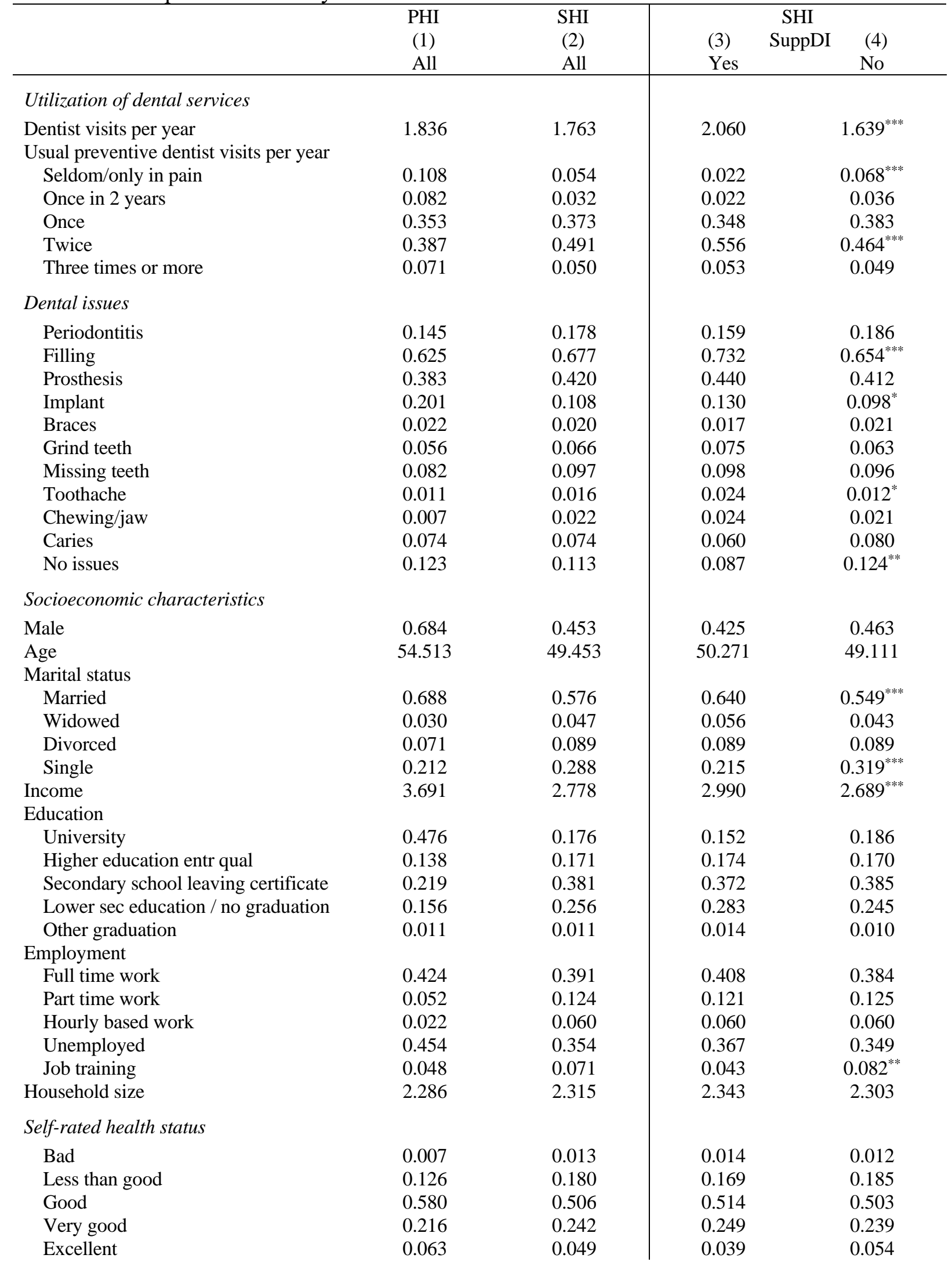




\begin{tabular}{|c|c|c|c|c|}
\hline & $\begin{array}{c}\text { PHI } \\
\text { (1) } \\
\text { All } \\
\end{array}$ & $\begin{array}{c}\text { SHI } \\
(2) \\
\text { All } \\
\end{array}$ & $\begin{array}{l}(3) \\
\text { Yes }\end{array}$ & $\begin{array}{l}(4) \\
\text { No } \\
\end{array}$ \\
\hline \multicolumn{5}{|c|}{ Proxies for risk preferences and health-related behavior } \\
\hline Number of other SuppHIs & 1.156 & 0.507 & 1.179 & $0.226^{* * *}$ \\
\hline Care about health & 3.572 & 3.505 & 3.502 & 3.507 \\
\hline Never smoker & 0.543 & 0.558 & 0.531 & 0.569 \\
\hline BMI & 26.494 & 26.419 & 26.529 & 26.373 \\
\hline Activity & 4.123 & 3.937 & 4.024 & 3.901 \\
\hline \multicolumn{5}{|l|}{ Diet } \\
\hline Fruits & 3.171 & 3.219 & 3.266 & 3.199 \\
\hline Vegetables & 3.152 & 3.078 & 3.143 & $3.052^{* *}$ \\
\hline Fast food & 1.825 & 1.821 & 1.824 & 1.820 \\
\hline Sweets & 2.353 & 2.411 & 2.428 & 2.404 \\
\hline Observations & 269 & 1,403 & 414 & 989 \\
\hline
\end{tabular}

Notes: Only individuals without missing values are considered. Income is measured in $€ 1,000$ intervals from $<€ 1,000$ up to $>€ 5,000$ monthly net household income. Activity: never $=1$ to daily $=6$. Diet: never/seldom $=1$ to daily $=4$. The level of significance for the statistical differences in a two-sided $t$-test between the two groups (see columns 3 and 4 ) is designated as follows: $* \mathrm{p}<.10 ; * * \mathrm{p}<.05 ; * * * \mathrm{p}<.01$.

To test for selection effects, we must find an appropriate measure for the financial risk associated with dental treatments. Because our data include no information on specific type of dental care or resulting expenditure for dental treatments, we cannot fully measure individual risk. Rather, we proxy risk by the number of dentist visits. The individuals were asked about the number of dentist visits in the previous twelve months. Table 1 shows that SuppDI policyholders go to the dentist more often than the comparison group. This finding might indicate that SuppDI policyholders are higher risks as they are also more likely to have a dental implant or dental filling and less likely to have no dental problems. Simply comparing the numbers for SuppDI enrollees and non-enrollees, however, is inadequate for risk assessment because the former may also be more likely to have annual check-ups. In fact, Table 1 confirms that SuppDI policyholders tend to have more preventive dentist visits than non-enrollees.

To improve our risk measurement, we adjust our risk proxy to disentangle acute treatment visits from preventive check-ups. Fig. 1 shows the distribution of dentist visits for the whole sample of individuals with SHI. As is evident, many individuals go to the dentist only once or 
twice a year, which indicates actual treatment or a dental check-up. ${ }^{11}$ Since SHI only cover two annual check-ups, we assume that three or more annual dentist visits clearly point to acute treatment. We thus transform our variable for risk (DentVisits) into a dummy equal to 1 if an individual went to the dentist more than twice in the previous year, and 0 otherwise. This transformation of the count variable, also used by Godfried et al. (2001), should minimize incorrect measurement of preventive dentist visits as a proxy for risk. In our robustness checks, we consider alternative specifications of the main dependent variable as well as an alternative risk proxy (Section 5.2).

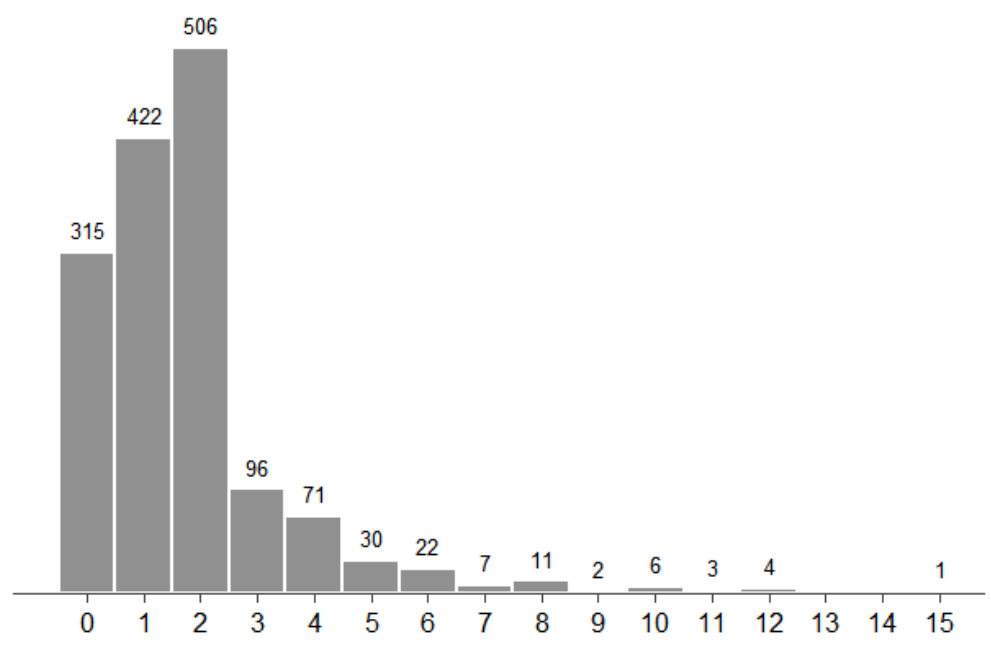

Fig. 1 Number of dentist visits for all individuals with SHI

\footnotetext{
${ }^{11}$ SHI members have a financial incentive to go for regular dental check-ups because if they do so during the 5 or 10 years preceding treatment, they receive higher benefits for dental prostheses.
} 


\subsection{Econometric Approach}

In a first step, we analyse the coverage-risk correlation to test for asymmetric information in the aggregate. Here, we apply two approaches which have been used in several previous studies (Cohen and Siegelman 2010). In our first approach ("one-equation approach"), we estimate the relation between the ex-post risk of an individual with respect to dental treatment and the SuppDI coverage by specifying the following linear probability model (LPM):

$$
P(\text { DentVisits }=1 \mid \text { SuppDI, } X, C)=\alpha_{0}+\alpha_{1} \text { SuppDI }+\alpha_{2} X+\alpha_{3} C
$$

DentVisits is our risk proxy as described in the previous section. SuppDI equals 1 if an individual has SuppDI, 0 otherwise. As the premiums for SuppDIs are generally risk adjusted, we include the vector $X$ to control for the risk classification in SuppDI policies. In line with the pricing of all German health insurers offering SuppDI, we include the insured's age ${ }^{12}$ and gender ${ }^{13}$. As insurers may ask applicants about missing teeth, past dental prostheses and advised dental or orthodontic treatment, we also include whether the individual has a dental prosthesis, a dental implant or missing teeth to be more conservative and to reflect the more thorough risk classification used only by some insurance companies. All these variables are included in nonparametric form and fully interacted. Finally, we control in our models for the usual number of annual dentist visits for patients without any major dental issues. We assume these to represent preventive dentist visits (vector $C$ ). ${ }^{14}$ Hence, this should capture overly cautious individuals, i.e. those getting more than the recommended two annual check-ups. In addition, we control for the

\footnotetext{
${ }^{12}$ As the data are only cross-sectional, we cannot include characteristics related to time of contract finalization. As a proxy, we use current information from the survey. In fact, age at contract entry is decisive for risk classification; however, since the survey does not report this datum, we control for the age of the insured at time of survey. We assume this bias to be relatively small since the majority of policies were finalized after the 2004 health care reform. ${ }^{13}$ As our survey data are from 2011, the introduction of unisex tariffs in December 2012 does not affect our analysis. ${ }^{14}$ Possible answers to the correspondent survey item are "three or more times a year," "about twice a year," "about once a year," "about once in two years," or "seldom, only in pain."
} 
individuals' fear of the dentist, which might capture possible skipping of annual check-ups or an avoidance of necessary treatments. ${ }^{15}$ Because the dependent variable is dichotomous, we also estimate a probit model.

In our second approach ("two-equation approach"), we rely on the bivariate probit model introduced by Chiappori and Salanié (2000) with the following two equations:

$$
\begin{aligned}
& \text { DentVisits }=\mathbf{1}\left(\beta_{1} X+\beta_{2} C+\varepsilon>0\right) \\
& \text { SuppDI }=\mathbf{1}\left(\gamma_{1} X+\gamma_{2} C+\eta>0\right)
\end{aligned}
$$

The specifications of the variables are the same as in equation (1). In this approach, we regress both our risk proxy DentVisits and our proxy for insurance coverage SuppDI conditional on $X$ and the vector $C$. Testing the independency of the residuals by the correlation coefficient $\rho(\varepsilon, \eta)$ enables to determine the relationship between DentVisits and SuppDI. Finding a correlation between the residuals that is significantly different from zero, i.e. $\rho(\varepsilon, \eta) \neq 0$, indicates that DentVisits and SuppDI are correlated. This finding would point to the existence of asymmetric information.

The sign of the coefficient of interest $\alpha_{1}$ in equation (1) as well as the correlation coefficient $\rho(\varepsilon, \eta)$ based on equation (2) and (3) indicate the dominant selection type in the aggregate. Identifying that $\alpha_{1}$ or $\rho(\varepsilon, \eta)$ is not significantly different from zero may be explained by different effects. First, it could indicate that asymmetric information in the SuppDI market is empirically negligible. Second, it could lead to a false rejection of asymmetric information when both adverse and advantageous selection types offset each other in the

\footnotetext{
${ }^{15}$ Measured by a 6-item scale from "no fear" to "panic."
} 
insurance market. The latter is unlikely to result in an equilibrium that is first best (Finkelstein and McGarry 2006). Third, an insignificant coverage-risk correlation could also be due to the existence of advantageous selection and an offsetting effect of insurance coverage on the use of dental services positively affecting the coverage-risk correlation. Note that the latter may be the classical ex-post moral hazard effect or other positive effects of insurance coverage on the use of dental services. ${ }^{16}$

Some studies (e.g., Manning et al. 1986; Meyerhoefer et al. 2014) find that having dental insurance positively affects utilization of dental services. However, there is also empirical evidence (see Grembowski et al. 1988 for a review) that documents a rather low price elasticity for dental services. Furthermore, Meyerhoefer, Zuvekas, and Manski (2014), for instance, find that the use of dental services is significantly increased for people holding a dental insurance, but insensitive to variation of out-of-pocket costs. Consistent with previous studies (Manning et al. 1986; Mueller and Monheit 1988), this finding indicates that varying the mere level of dental insurance coverage does not considerably impact the use of dental services. Thus, we cannot reject a possible bias caused by a causal effect of insurance coverage on dental care use. However, we conjecture that the probability of a causal effect of SuppDI coverage in Germany is rather low since each SHI enrollee is fully covered for basic tooth preservation and at least for $50 \%$ of the cost of standard treatment for dental prostheses. We suggest that an insignificant coveragerisk correlation arises at least to some extent from an offsetting effect of heterogeneous selection.

To get a clearer picture on the selection behavior in the SuppDI market, we test for the potential sources of selection effects in a second step. Consistent with previous studies (e.g.,

\footnotetext{
${ }^{16}$ It should be noted, that a positive effect of insurance coverage on the utilization of dental care is not a sufficient condition for ex-post moral hazard and a related welfare loss. If insurance coverage gives individuals access to unaffordable health care (Nyman 1999), or provides incentives to use more preventive health care, an increased utilization of dental services due to insurance coverage is not inefficient.
} 
Browne and Zhou-Richter 2014; Finkelstein and McGarry 2006), we add potential drivers to our basic model in equation (4) and (5):

$$
\begin{aligned}
& \text { DentVisits }=\mathbf{1}\left(\theta_{1} X+\theta_{2} C+\theta_{3} D+\varphi>0\right) \\
& \text { SuppDI }=\mathbf{1}\left(\vartheta_{1} X+\vartheta_{2} C+\vartheta_{3} D+\phi>0\right)
\end{aligned}
$$

The interpretation of the equations generally follows equation (2) and (3). Vector $D$ represents potential drivers for selection. Looking at $\theta_{3}$ and $\vartheta_{3}$ enables us to examine which characteristics are drivers for selection. Identifying an attribute that correlates positively with the uptake of SuppDI $\left(\vartheta_{3}>0\right)$ and with the risk of loss $\left(\theta_{3}>0\right)$ and that substantially changes the coverage-risk correlation represented by $\rho(\varphi, \phi)$ in a negative direction (i.e. $\rho(\varphi, \phi)<\rho(\varepsilon, \eta))$ can be considered as a source of adverse selection. Conversely, finding a characteristic with opposite signs for the correlation with SuppDI and risk (e.g., $\vartheta_{3}>0 \&$ $\left.\theta_{3}<0\right)$ and which leads to $\rho(\varphi, \phi)>\rho(\varepsilon, \eta)$ can be interpreted as a source of advantageous selection. It should be noted that this holds irrespective of a possible bias caused by moral hazard or, more generally, a positive effect of SuppDI on our risk proxy.

In our analysis, we consider several potential sources of advantageous selection. We focus on characteristics related to risk preferences since risk aversion may be considered as a primary cause of advantageous selection based on de Meza and Webb (2001). Since we cannot measure risk aversion directly, we test a large set of factors that have been related to individual risk preferences in previous studies (Browne and Zhou-Richter 2014; Buchmueller et al. 2013; Cutler et al. 2008; Finkelstein and McGarry 2006). First, we examine risky or risk-reducing behavior with variables on the individual's care about his own health ("Care about health"), on smoking ("Never a smoker"), on the frequency of physical activities ("Physical activities"), such as sports 
or gardening, and on the frequency of eating rather healthy food ("Fruits" and "Vegetables") and unhealthy food ("Fast Food" and "Sweets"). Based on the assumption that these measures are likely to be related to risk aversion, we predict that people with a preventive health behavior are more likely to hold SuppDI and less likely to visit dentists for acute treatment. As another characteristic related to risk preferences, we test the preference for insurance proxied by holding of other SuppHIs except SuppDI ("Preference for insurance"). ${ }^{17}$ Examples for further SuppHIs in our data are a daily sickness or hospital daily benefits insurance and a supplemental hospital insurance covering the treatment by chief physician and a single or double hospital bed. ${ }^{18}$ Based on de Meza and Webb (2001), we argue that people holding many SuppHIs buy SuppDI because of their inner need for security and their generally higher preference for insurance on the one hand and are more likely to take precautions leading to lower ex-post risk on the other hand. ${ }^{19}$

Based on classical adverse selection models (e.g., Rothschild and Stiglitz 1976) and empirical findings (e.g., Browne and Zhou-Richter 2014) we examine self-rated health as a potential source of adverse selection. The rationale is that people with private information about their bad health are more likely to expect future dental treatments and are more likely to buy SuppDI. We measure self-assessed health by five dichotomous indicators for each level of health (e.g., "Good"). Finally, we test socioeconomic characteristics, including income ("Income"), employment (e.g., "Full time"), marital status (e.g., "Married") household size (“HH size”) and

\footnotetext{
${ }^{17}$ The holding of several SuppHIs can basically be driven by the individual's preference for insurance coverage and by supplier behavior. However, to the best of our knowledge, insurance companies do not offer discounts for individuals buying more than one SuppHI. Moreover, the share of SHI enrollees with one specific type of SuppHI varies substantially. For instance, many SHI enrollees with a SuppDI do not hold a supplemental hospital insurance (Grabka 2014). Thus, in line with Browne and Zhou-Richter (2014), we suggest that the holding of several SuppHIs is more likely to be driven by the individual's preference for insurance.

${ }^{18}$ Further examples are a SuppHI with benefits for eyeglasses, drugs, and other medication, a supplemental LTCI, a SuppHI for alternative healing methods and naturopathy, a SuppHI for cures and special medical check-ups and a SuppHI for treatment by a private physician.

${ }^{19}$ Note that empirical evidence (e.g., Chen and Hunter 1996; Lang et al. 1994; Levin and Shenkman 2004) shows that dental prevention, such as periodic dental check-ups or flossing, are predominantly positively related to dental health. See Petersen (2003), for instance, for a discussion on oral disease prevention.
} 
education ("e.g., Higher education entr qual") as potential drivers for selection. Based on previous findings (e.g., Buchmueller et al. 2013; Fang et al. 2008), we suggest that a better socioeconomic status, such as higher income, contributes to advantageous selection in the SuppDI market.

The identification of such drivers requires a discussion about potential endogeneity of the variables in question. On the one hand, reverse causality could challenge the interpretation of our results if driver $D$ is at least partly caused by either DentVisits or SuppDI. On the other hand and despite our rich set of covariates, the observed relationship between $D$ and both dependent variables might stem from unobserved factors that causally affect all our variables of interest and create a spurious correlation. Given the cross-sectional nature of our data the most common approach to test for endogeneity is the use of instrumental variables (IV) (Angrist and Pischke 2009). However, as in our case, valid instruments are often unavailable making clear identification difficult. For such cases, Lewbel $(2012,2018)$ has suggested the use of internally constructed instruments that can be obtained from heteroscedasticity of the structural equations. This method has recently been applied as a robustness check in a number of studies lacking valid classical instruments or only having weak instruments (Awaworyi Churchill et al. 2017a; Awaworyi Churchill et al. 2017b; Le Moglie et al. 2015; Lin et al. 2017). Identification in Lewbel's method relies on comparably less restrictive assumptions. In the presence of exogenous variables and heteroscedasticity, identification can be achieved without the classical exclusion restriction of a specific instrument and relies on the heteroscedasticity of the error in both structural equations of the two-stage estimation. We provide the results of this approach in our section on robustness checks (Section 5.2). 


\section{Results}

\subsection{Evidence of Heterogeneous Selection}

We first analyse the data using the two aforementioned approaches to test for asymmetric information in insurance markets. Table 2 summarizes the results of the one- and two-equation approach using different estimation techniques. Regressing dental risk on the dummy for holding SuppDI (one-equation approach), while controlling for pricing characteristics, shows no significant difference between the groups both using a LPM and a Probit estimation (column 1 and 2). Similarly, for the two-equation approach, we do not find a significant correlation between the residuals obtained from the two regressions of risk and insurance demand on pricing characteristics. This holds both when using a bivariate probit model (column 3) and when checking the independence of the residuals after estimating equation (2) and (3) separately by a LPM (column 1) and a Probit model (column 2).

Table 2 Coverage-Risk Correlation

\begin{tabular}{|c|c|c|c|}
\hline Dependent Variable & $\begin{array}{c}(1) \\
\text { LPM } \\
\end{array}$ & $\begin{array}{l}\text { entist visits >2 } \\
\text { (2) } \\
\text { Probit } \\
\end{array}$ & $\begin{array}{c}(3) \\
\text { Biprobit }\end{array}$ \\
\hline $\begin{array}{l}\text { Coefficient from regression of dentist } \\
\text { visits on SuppDI } \\
\text { Observations }\end{array}$ & $\begin{array}{c}0.0246 \\
(0.022) \\
1,474 \\
\end{array}$ & $\begin{array}{c}0.1118 \\
(0.097) \\
1,375 \\
\end{array}$ & \\
\hline $\begin{array}{l}\text { Correlation coefficient of residuals } \\
\rho(\varepsilon, \eta) \\
\text { Observations }\end{array}$ & $\begin{array}{c}0.0319 \\
(\mathrm{p}=0.221) \\
1,474\end{array}$ & $\begin{array}{c}0.0336 \\
(\mathrm{p}=0.214) \\
1,375\end{array}$ & $\begin{array}{c}0.0686 \\
(p=0.236) \\
1,474\end{array}$ \\
\hline
\end{tabular}

Based on these results, one could conclude the absence of asymmetric information in the German market for SuppDI. Since this finding can, however, also be explained by heterogeneous selection behaviour, we exploit the rich data set and test for sources of selection. Table 3 shows the results for adding each potential driver for selection separately (column 1 and 2) and adding 
those potential drivers simultaneously (column 3 and 4) to our basic bivariate probit model. Here, we cluster our variables along two main categories: first, a set of factors related to risk preferences and, second, socioeconomic characteristics including self-rated health. Among the attributes related to risk preferences, we only find that preference for insurance significantly and positively correlates with the demand for SuppDI, but negatively with dental risk. To interpret preference for insurance as a driver for selection in the SuppDI market, the issue of causality in the relationship of preference for insurance with SuppDI and risk is important. If the risk covered by any SuppHI except SuppDI correlates with the number of dentist visits through other ways than the link of risk aversion, our estimates would be biased. Admittedly, we doubt that worse dental health is likely to influence the decision to buy one of the other SuppHI products. Moreover, other health issues that increase the likelihood of other SuppHIs, such as supplemental hospital insurance, may not affect dental care, being a very distinct field. Nevertheless, if an individual's general health correlates negatively with overall insurance coverage and positively with dental health, any potential bias is likely to be positive. The relationships of preference for insurance with our dependent variables remain robustly significant when we control for further covariates, including overall health, in column 3 and 4.

Furthermore, the correlation of the residuals turns from insignificant (Table 2) to significantly positive when controlling for this attribute. In line with Browne and Zhou-Richter (2014), these findings indicate that preference for insurance is a source of advantageous selection. Self-rated health correlates as expected significantly negatively with dental risk, but the correlation with the holding of SuppDI is insignificant. This finding does not support the prediction that self-assessed health is a source of adverse selection in this market. The correlation coefficient of the bivariate probit model after controlling for all potential drivers for selection $\left(\rho(\varphi, \phi)=0.1482^{* *}\right)$ suggests that there are still unobserved characteristics that correlate 
positive with insurance demand and dental risk and hence offset the advantageous selection driven by preference for insurance.

Table 3 Sources of Selection

\begin{tabular}{|c|c|c|c|c|c|}
\hline & (1) & \multicolumn{2}{|c|}{$\begin{array}{c}\text { (2) } \\
\text { Adding potential sources } \\
\text { separately }\end{array}$} & \multicolumn{2}{|c|}{$\begin{array}{c}\text { (4) } \\
\text { Adding all potential sources } \\
\text { simultaneously }\end{array}$} \\
\hline & DentVisits & SuppDI & $\rho(\varphi, \phi)$ & DentVisits & SuppDI \\
\hline \multicolumn{6}{|l|}{ Risk preferences } \\
\hline Care about health & $\begin{array}{c}-0.0503 \\
(0.061)\end{array}$ & $\begin{array}{c}-0.0075 \\
(0.051)\end{array}$ & $\begin{array}{c}0.0671 \\
(\mathrm{p}=0.247)\end{array}$ & $\begin{array}{c}-0.0550 \\
(0.070)\end{array}$ & $\begin{array}{l}-0.0949 \\
(0.065)\end{array}$ \\
\hline Never smoker & $\begin{array}{l}0.0495 \\
(0.094)\end{array}$ & $\begin{array}{l}-0.0711 \\
(0.078)\end{array}$ & $\begin{array}{c}0.0659 \\
(p=0.259)\end{array}$ & $\begin{array}{l}-0.0055 \\
(0.101)\end{array}$ & $\begin{array}{l}-0.0548 \\
(0.091)\end{array}$ \\
\hline BMI & $\begin{array}{c}-0.0121 \\
(0.011)\end{array}$ & $\begin{array}{l}0.0024 \\
(0.007)\end{array}$ & $\begin{array}{c}0.0626 \\
(p=0.284)\end{array}$ & $\begin{array}{r}-0.0125 \\
(0.011)\end{array}$ & $\begin{array}{r}-0.0113 \\
(0.008)\end{array}$ \\
\hline Physical activity & $\begin{array}{l}-0.0415 \\
(0.029)\end{array}$ & $\begin{array}{l}0.0126 \\
(0.025)\end{array}$ & $\begin{array}{c}0.0690 \\
(p=0.234)\end{array}$ & $\begin{array}{l}-0.0316 \\
(0.032)\end{array}$ & $\begin{array}{l}-0.0155 \\
(0.030)\end{array}$ \\
\hline Fruits & $\begin{array}{l}0.0130 \\
(0.058)\end{array}$ & $\begin{array}{l}0.0249 \\
(0.049)\end{array}$ & $\begin{array}{c}0.0660 \\
(p=0.256)\end{array}$ & $\begin{array}{c}-0.0156 \\
(0.067)\end{array}$ & $\begin{array}{l}0.0240 \\
(0.063)\end{array}$ \\
\hline Vegetables & $\begin{array}{l}0.0223 \\
(0.069)\end{array}$ & $\begin{array}{c}0.1195 * * \\
(0.059)\end{array}$ & $\begin{array}{c}0.0670 \\
(\mathrm{p}=0.249)\end{array}$ & $\begin{array}{l}0.0259 \\
(0.080)\end{array}$ & $\begin{array}{l}0.0371 \\
(0.075)\end{array}$ \\
\hline Fast food & $\begin{array}{l}-0.0366 \\
(0.076)\end{array}$ & $\begin{array}{l}-0.0012 \\
(0.067)\end{array}$ & $\begin{array}{c}0.0826 \\
(\mathrm{p}=0.158)\end{array}$ & $\begin{array}{c}-0.0396 \\
(0.081)\end{array}$ & $\begin{array}{l}0.0018 \\
(0.079)\end{array}$ \\
\hline Sweets & $\begin{array}{l}0.0515 \\
(0.058)\end{array}$ & $\begin{array}{l}0.0283 \\
(0.050)\end{array}$ & $\begin{array}{c}0.0759 \\
(p=0.192)\end{array}$ & $\begin{array}{l}0.0446 \\
(0.064)\end{array}$ & $\begin{array}{l}0.0441 \\
(0.058)\end{array}$ \\
\hline Preference for insurance & $\begin{array}{c}-0.1166^{* *} \\
(0.049)\end{array}$ & $\begin{array}{c}0.7902 * * * \\
(0.056)\end{array}$ & $\begin{array}{c}0.1494 * * \\
(p=0.016)\end{array}$ & $\begin{array}{c}-0.1373 * * * \\
(0.052)\end{array}$ & $\begin{array}{c}0.7665 * * * \\
(0.058)\end{array}$ \\
\hline \multicolumn{6}{|l|}{ Socioeconomic characteristics } \\
\hline Employment & & & $\begin{array}{c}0.0689 \\
(p=0.234)\end{array}$ & & \\
\hline Part time work & $\begin{array}{l}0.0355 \\
(0.154)\end{array}$ & $\begin{array}{c}-0.2161 \\
(0.132)\end{array}$ & & $\begin{array}{l}0.1140 \\
(0.163)\end{array}$ & $\begin{array}{c}-0.0678 \\
(0.157)\end{array}$ \\
\hline Hourly based work & $\begin{array}{l}-0.0335 \\
(0.214)\end{array}$ & $\begin{array}{c}-0.0126 \\
(0.175)\end{array}$ & & $\begin{array}{c}-0.0479 \\
(0.238)\end{array}$ & $\begin{array}{l}0.0833 \\
(0.210)\end{array}$ \\
\hline Unemployed & $\begin{array}{c}-0.1329 \\
(0.155)\end{array}$ & $\begin{array}{l}-0.0397 \\
(0.129)\end{array}$ & & $\begin{array}{c}-0.1076 \\
(0.175)\end{array}$ & $\begin{array}{l}0.0108 \\
(0.154)\end{array}$ \\
\hline Job Training & $\begin{array}{l}-0.2067 \\
(0.302)\end{array}$ & $\begin{array}{l}-0.2998 \\
(0.257)\end{array}$ & & $\begin{array}{l}-0.4063 \\
(0.318)\end{array}$ & $\begin{array}{l}-0.0836 \\
(0.280)\end{array}$ \\
\hline Education & & & $\begin{array}{c}0.0761 \\
(p=0.191)\end{array}$ & & \\
\hline University & $\begin{array}{c}0.2690 * * \\
(0.137)\end{array}$ & $\begin{array}{c}-0.1828 \\
(0.119)\end{array}$ & & $\begin{array}{l}0.2286 \\
(0.152)\end{array}$ & $\begin{array}{l}-0.2067 \\
(0.145)\end{array}$ \\
\hline Higher education entr qual & $\begin{array}{c}0.3969 * * * \\
(0.151)\end{array}$ & $\begin{array}{r}-0.0313 \\
(0.127)\end{array}$ & & $\begin{array}{c}0.2968 * \\
(0.162)\end{array}$ & $\begin{array}{r}-0.1414 \\
(0.145)\end{array}$ \\
\hline Sec school leaving certificate & $\begin{array}{c}0.2467 * * \\
(0.121)\end{array}$ & $\begin{array}{c}-0.0519 \\
(0.098)\end{array}$ & & $\begin{array}{c}0.2395^{*} \\
(0.129)\end{array}$ & $\begin{array}{c}-0.2145^{*} \\
(0.114)\end{array}$ \\
\hline Other graduation & $\begin{array}{l}0.1937 \\
(0.408)\end{array}$ & $\begin{array}{l}0.2154 \\
(0.360)\end{array}$ & & $\begin{array}{l}0.2293 \\
(0.440)\end{array}$ & $\begin{array}{l}0.2362 \\
(0.394)\end{array}$ \\
\hline Marital status & & & $\begin{array}{c}0.0628 \\
(p=0.283)\end{array}$ & & \\
\hline Married & $\begin{array}{l}0.0348 \\
(0.125)\end{array}$ & $\begin{array}{c}0.3341 * * * \\
(0.104)\end{array}$ & & $\begin{array}{l}0.1054 \\
(0.149)\end{array}$ & $\begin{array}{c}0.2698 * * \\
(0.138)\end{array}$ \\
\hline Widowed & $\begin{array}{l}0.2227 \\
(0.229)\end{array}$ & $\begin{array}{l}0.3357 \\
(0.214)\end{array}$ & & $\begin{array}{l}0.2901 \\
(0.237)\end{array}$ & $\begin{array}{l}0.2368 \\
(0.245)\end{array}$ \\
\hline Divorced & $\begin{array}{l}-0.1151 \\
(0.194)\end{array}$ & $\begin{array}{l}0.2329 \\
(0.159)\end{array}$ & & $\begin{array}{c}-0.0899 \\
(0.204)\end{array}$ & $\begin{array}{c}0.4086^{* *} \\
(0.180)\end{array}$ \\
\hline
\end{tabular}




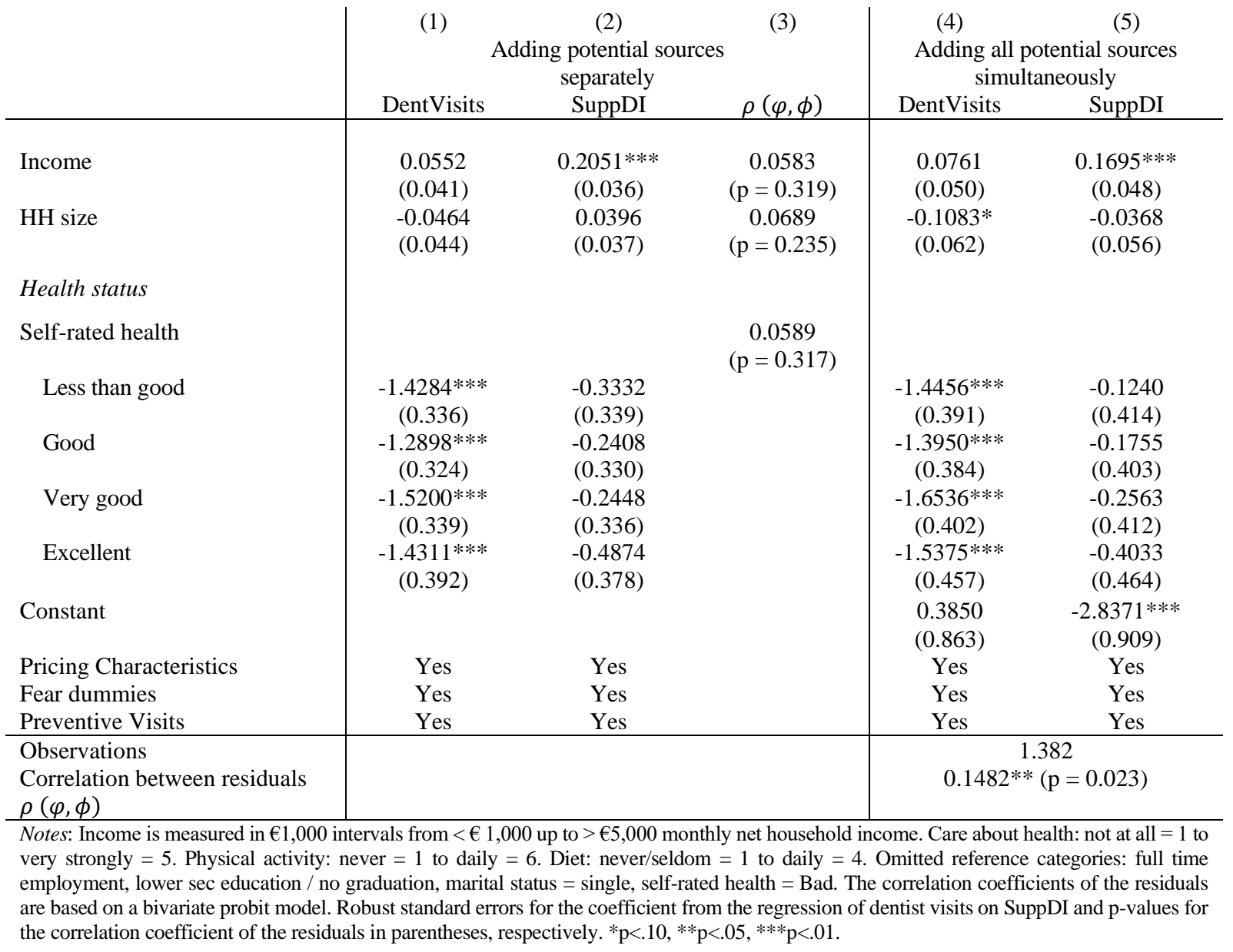

In an additional test, we provide support for our assumption that people with a higher preference for insurance are better dental risks and, therefore, go to the dentist less often. We analyzed the share of individuals without any dental problems and self-rated health. In Table 4, we report the differences in means within the first and last two columns. The first row shows that the share of individuals without SuppDI coverage (12.6\%) who are not suffering from any dental problems is significantly higher than the respective share of SuppDI policyholders $(8.9 \%)$. That indicates that SuppDI policyholders are higher risk types in the aggregate. To get a clearer picture on preference for insurance as a driver for advantageous selection, column 3 and 4 show a comparison of SuppDI policyholders with high (i.e. $>2$ additional SuppHIs) and low preference for insurance ( $\leq 2$ additional SuppHIs). 17.2\% of SuppDI policyholders with high preference for insurance have no dental issues versus only $7.4 \%$ of SuppDI policyholders with low preference 
for insurance. This significantly lower result is consistent with our earlier estimations showing that multidimensional private information leads to advantageous selection by some individuals. People with a high preference for insurance seem to have better dental health, an observation supported by the fact that their mean of self-rated overall health is slightly higher than that of the comparison group, which holds also true when comparing share of individuals with at least "good" health.

Table 4 Differences by Insurance and Subgroup

\begin{tabular}{lcc|cc}
\hline Variable & $(1)$ & $(2)$ & $(3)$ & $(4)$ \\
No SuppDI & SuppDI & $\leq 2$ other SuppHIs & >2 other SuppHIs \\
\hline No dental issues (1=yes) & 0.126 & $0.089^{* *}$ & 0.074 & $0.172^{* *}$ \\
Observations & 1,067 & 429 & 365 & 64 \\
\hline Self-rated health (SRH) & & & & $3.286^{*}$ \\
Ordinal & 3.135 & 3.120 & 3.092 & $0.906^{*}$ \\
Binary (1=SRH>2) & 0.799 & 0.816 & 0.800 & 63 \\
Observations & 1,059 & 423 & 360 & 63 \\
\hline
\end{tabular}

Notes: Differences are tested by Fisher's exact test for binary variables and by the Wilcoxon rank-sum test for ordinal specifications between the two groups in column (1) and (2) as well as between the groups in column (3) and (4). When measuring self-rated health by an ordinal variable, the possible range is $1=\operatorname{Bad}$ to $5=$ Excellent. The level of significance is designated as follows: $* \mathrm{p}<.10$; $* * \mathrm{p}<.05 ; * * * \mathrm{p}<.01$.

\subsection{Robustness Checks}

The main results are based on distinct specifications of the risk proxy (DentVisits) and the proxy for preference for insurance (Preference for insurance) as the main driver for selection. To emphasize the robustness of our results, we test several different specifications of those variables and thereby assess the sensitivity of our main results. Table 5 presents how different specifications of the variable for dentist visits affect its correlation with the holding of SuppDI in the LPM and with preference for insurance in the bivariate probit model. The correlation between SuppDI and dentist visits remains insignificant when varying the cutoff for the dummy variable for dentist visits and controlling for the same set of covariates as in our basic LPM. However, for the linear specification, the coverage-risk estimate shows a positive and significant correlation between SuppDI and dentist visits at least on a 10\% level, which might indicate the existence of 
a positive effect of SuppDI on our risk proxy or adverse selection in the aggregate. Alternatively, the positive association could result from inadequately capturing some non-acute dentist visits of highly risk averse SuppDI policyholders, which is why we refrained from using this specification in our main model. In line with results from Table 3, when controlling for potential drivers, including preference for insurance, the association between SuppDI and dental risk becomes positively significant for most specifications. The correlation of dentist visits and preference for insurance remains robustly significant for some, but not all, other specifications of dentist visits. In column 8 of Table 5, we additionally use the dummy variable indicating no dental issues, already presented in Table 4, as an alternative risk proxy. Results are similar to dentist visits as we do not find a significant coverage-risk correlation. Moreover, people with a high preference for insurance are more likely to have no dental issues, i.e. they are more likely to be a low risk type.

Table 5 Sensitivity Test for the Specification of the Dependent Variable

\begin{tabular}{|c|c|c|c|c|c|c|c|c|}
\hline \multirow{2}{*}{$\begin{array}{l}\text { Dependent } \\
\text { Variable }\end{array}$} & \multicolumn{7}{|c|}{ Dentist visits } & \multirow{2}{*}{$\begin{array}{c}\text { No } \\
\text { dental } \\
\text { issues } \\
(8) \\
\text { Cutoff }>0\end{array}$} \\
\hline & $\begin{array}{c}(1) \\
\text { Cutoff }>0\end{array}$ & $\begin{array}{c}(2) \\
\text { Cutoff }>1\end{array}$ & $\begin{array}{c}\text { (3) } \\
\text { Cutoff }>2\end{array}$ & $\begin{array}{c}\text { (4) } \\
\text { Cutoff }>3\end{array}$ & $\begin{array}{c}\text { (5) } \\
\text { Cutoff }>4\end{array}$ & $\begin{array}{c}\text { (6) } \\
\text { Cutoff }>5\end{array}$ & $\begin{array}{c}(7) \\
\text { Linear }\end{array}$ & \\
\hline \multicolumn{9}{|l|}{$\begin{array}{l}\text { Independent } \\
\text { Variable }\end{array}$} \\
\hline \multirow{4}{*}{ SuppDI } & $\begin{array}{l}0.0357 \\
(0.022) \\
\end{array}$ & $\begin{array}{c}L P M \\
0.0169 \\
(0.027) \\
\end{array}$ & $\begin{array}{c}\text { LS only con } \\
0.0246 \\
(0.022)\end{array}$ & $\begin{array}{c}\text { lling for un } \\
0.0250 \\
(0.019)\end{array}$ & $\begin{array}{c}\text { writing anc } \\
0.0207 \\
(0.015)\end{array}$ & $\begin{array}{l}\text { ctor } C \\
0.0160 \\
(0.013)\end{array}$ & $\begin{array}{l}0.1873^{*} \\
(0.103)\end{array}$ & $\begin{array}{c}\text { without C } \\
-0.0067 \\
(0.017)\end{array}$ \\
\hline & \multicolumn{7}{|c|}{ LPM controlling for underwriting, vector $C+$ all potential drivers for selection } & without $C$ \\
\hline & 0.0384 & $0.0562^{*}$ & $0.0505^{*}$ & 0.0355 & $0.0389^{* *}$ & $0.0322^{* *}$ & $0.3267^{* * *}$ & -0.0243 \\
\hline & $(0.025)$ & $(0.031)$ & $(0.026)$ & $(0.022)$ & $(0.017)$ & $(0.016)$ & $(0.119)$ & $(0.019)$ \\
\hline \multirow{4}{*}{$\begin{array}{l}\text { Preference for } \\
\text { insurance }\end{array}$} & \multicolumn{7}{|c|}{ Bivariate probit model controlling for underwriting and vector $C$} & without $C$ \\
\hline & $\begin{array}{r}-0.0013 \\
(0.041) \\
\end{array}$ & $\begin{array}{c}-0.0841^{* *} \\
(0.039)\end{array}$ & $\begin{array}{c}-0.1166^{* *} \\
(0.049)\end{array}$ & $\begin{array}{c}-0.0706 \\
(0.059) \\
\end{array}$ & $\begin{array}{c}-0.10671 \\
(0.067) \\
\end{array}$ & $\begin{array}{c}-0.1543^{* *} \\
(0.076)\end{array}$ & & $\begin{array}{l}0.1086^{*} \\
(0.059)\end{array}$ \\
\hline & \multicolumn{7}{|c|}{ Bivariate probit model controlling for underwriting, vector $C+$ all potential drivers for selection } & without $C$ \\
\hline & $\begin{array}{l}0.0088 \\
(0.043)\end{array}$ & $\begin{array}{c}-0.0723^{*} \\
(0.041)\end{array}$ & $\begin{array}{c}-0.1373^{* * *} \\
(0.052)\end{array}$ & $\begin{array}{r}-0.1028 \\
(0.063)\end{array}$ & $\begin{array}{c}-0.1140 \\
(0.070)\end{array}$ & $\begin{array}{c}-0.1323^{*} \\
(0.075)\end{array}$ & & $\begin{array}{c}0.1123^{*} \\
(0.060)\end{array}$ \\
\hline
\end{tabular}

Notes: The list of all potential drivers of selection corresponds to the list of potential drivers used in Table 3 . The number of observations slightly varies between the specifications due to missing values. The cells for the linear specification of dentist visits in the bivariate probit model are left blank as this model is based on binary dependent variables. Robust standard errors in parentheses. *p<.10, **p<.05, ***p<.01. 
Table 6 shows the results of testing the sensitivity of the specification of our preference for insurance variable. Based on the bivariate probit model, we find that the results are quite robust when using a dummy variable for preference for insurance with different cutoffs. This supports our main findings shown in the previous section. ${ }^{20}$

Table 6 Sensitivity Test for the Specification of Preference for Insurance

\begin{tabular}{lcc} 
& & \\
& $(1)$ & $(2)$ \\
Dependent Variable & Dentist visits $>2$ & SuppDI \\
\hline Independent Variable & Preference for insurance & \\
& & \\
& Bivariate probit model controlling for underwriting and vector $C$ \\
Cutoff $>0$ & $-0.1701^{*}$ & $1.3128^{* * *}$ \\
& $(0.101)$ & $(0.085)$ \\
Cutoff $>1$ & $-0.3606^{* *}$ & $1.6146^{* * *}$ \\
& $(0.150)$ & $(0.125)$ \\
Cutoff $>2$ & $-0.5647^{* *}$ & $1.9151^{* * *}$ \\
& $(0.238)$ & $(0.219)$ \\
Linear & $-0.1166^{* *}$ & $0.7902^{* * *}$ \\
& $(0.049)$ & $(0.056)$ \\
Observations & 1,474 & 1,474 \\
& & \\
Cutoff $>0$ & Bivariate probit & model controlling for underwriting, vector C + all potential drivers for selection \\
& -0.1681 & $1.2887^{* * *}$ \\
Cutoff $>1$ & $(0.108)$ & $(0.092)$ \\
& $-0.4376^{* * *}$ & $1.5319^{* * *}$ \\
Cutoff $>2$ & $(0.162)$ & $(0.129)$ \\
& $-0.6365^{* *}$ & $1.8511^{* * *}$ \\
Linear & $(0.261)$ & $(0.218)$ \\
& $-0.1373^{* * *}$ & $0.7665^{* * *}$
\end{tabular}

This analysis is based on survey data. The survey items about dental health, however, only capture their extensive margin, but do not allow differentiating the intensity of a specific dental issue. For instance, we can observe if a participant has at least one missing tooth or not but we do not observe how many teeth are acutely missing. Thus, we cannot fully rule out a possible bias in the risk distribution in the overall market, as some insurers may reject applicants for SuppDI based on the intensity of their dental issues. Even though we know that rejections

\footnotetext{
${ }^{20}$ Testing for larger cutoffs for the variable Preference for insurance results in cell sizes of less than 10 observations.
} 
may occur due to missing teeth or dental prostheses, some insurers only reject applicants if the number exceeds a certain threshold, which cannot be identified in the data. To provide further insights into this potential problem, we split our sample and exclude all individuals that have at least one dental prosthesis, implant or missing tooth. Hence, similar to Finkelstein and McGarry (2006), we are able to test the coverage-risk correlation for a more homogeneous subsample of individuals as we can be certain that individuals in the remaining sample would not be rejected by insurers. Results in panel A of Table 7 support the non-significant relationship between dentist visits for acute treatments and SuppDI coverage. Similarly, preference for insurance remains a robust driver for advantageous selection (columns 3 and 4). The results in Panel B of Table 7 reveal that our findings for the alternative risk proxy, i.e. no dental issues, are similar to our findings for dentist visits (Panel A). ${ }^{21}$

Table 7 Coverage-Risk Correlation for Non-rejection Sample

\begin{tabular}{|c|c|c|c|c|}
\hline Dependent Variable & $\begin{array}{c}(1) \\
\text { LPM }\end{array}$ & $\begin{array}{c}\text { : Dentist } \\
(2) \\
\text { Probit }\end{array}$ & $\begin{array}{c}(3) \\
\text { Biprobit }\end{array}$ & $\begin{array}{c}\text { SuppDI } \\
(4) \\
\text { Biprobit }\end{array}$ \\
\hline \multicolumn{5}{|l|}{ Independent variable } \\
\hline SuppDI & $\begin{array}{l}0.0136 \\
(0.027)\end{array}$ & $\begin{array}{c}0.0703 \\
(0.155)\end{array}$ & & \\
\hline Preference for insurance & & & $\begin{array}{c}-0.1774^{*} \\
(0.096)\end{array}$ & $\begin{array}{c}0.7860^{* * * *} \\
(0.080)\end{array}$ \\
\hline Observations & 688 & 688 & 688 & 688 \\
\hline \multirow[t]{2}{*}{ Dependent Variable } & & No dent & & SuppDI \\
\hline & LPM & Probit & Biprobit & Biprobit \\
\hline \multicolumn{5}{|l|}{ Independent variable } \\
\hline SuppDI & $\begin{array}{r}-0.0141 \\
(0.035)\end{array}$ & $\begin{array}{c}-0.0506 \\
(0.126)\end{array}$ & & \\
\hline Preference for insurance & & & $\begin{array}{l}0.1093^{*} \\
(0.059)\end{array}$ & $\begin{array}{c}0.7616^{* * * *} \\
(0.075)\end{array}$ \\
\hline Observations & 702 & 702 & 702 & 702 \\
\hline
\end{tabular}

\footnotetext{
${ }^{21}$ The use of the restricted sample resolves a second issue concerning the alternative risk proxy presented in Table 5 (column 8). Specifically, the variables for dental health that we use for risk classification (e.g., missing teeth) perfectly predict whether individuals have any dental issues. Even though these observations do not get omitted by our statistical software, results remain remarkably similar between the two approaches.
} 
In addition to functional misspecifications, we also tested the robustness of our results using the IV approach proposed by Lewbel $(2012,2018)$. As a first step, we were required to reduce the number of variables used for risk classification $X$ in equation 4 and 5 from our main results. In Table 8 in the Appendix, we provide an analysis of different specifications of $X$ on the relationship between preference for insurance and our two dependent variables. Compared to our main approach using the full interaction, the observed results remain insensitive to different specifications of the risk classification variables, such as using no interaction. Our preferred specification for the IV models relates to an approach by Dionne et al. (2001) to use the predictions obtained from an auxiliary regression, regressing the respective outcome on all $X$ variables and their interactions. As shown in Table 8, results remain comparable and we are confident that any potential bias through different specifications between our main results and the robustness checks remains minimal.

The results from the IV approach are displayed in Table 9 in the Appendix. The methodological test statistics with regards to overidentification (Hansen J) and instrument strength (F-statistic) perform well, with few noteworthy exceptions. Panel A shows the results using preference for insurance as a continuous variable, while results in Panel B are based on a dichotomous specification. While the Lewbel approach is generally applicable in the case of binary endogenous regressors and dependent variables, Lewbel (2018) points out that the theoretical explanation of the underlying identification assumptions for such cases is less straightforward and results should therefore be treated with caution. However, the Breusch-Pagan test indicates strong support for heteroscedasticity in the first-stage regressions of all models presented in Table 9.

Overall, contrasting the coefficients for preference for insurance from OLS with those from the IV approach, we consider our main findings to be generally robust. In panel A and B, most coefficients for preference for insurance from the IV estimations are similar to those from 
the OLS estimations. In panel B, the relationship between preference for insurance and dental health measured by the absence of dental issues is positive in both the OLS and the IV estimations, but not statistically significant in the IV estimation.

\section{Conclusions}

In this paper, we analyze information asymmetry and related selection effects in the German SuppDI market. Applying the standard positive correlation test, our results provide no evidence that individuals with SuppDI are higher risk types than non-enrollees. Thus, in contrast to findings of Godfried et al. (2001), we find no support for the positive coverage-risk correlation in the aggregate as predicted by classic adverse selection models. Testing several potential sources of selection in a further step, we mainly identify the holding of other SuppHIs as a main driver for advantageous selection. This result remains robust even after we control for a comprehensive set of covariates. Our results suggest, however, that health-related behavior as another factor related to risk preferences, self-assessed health or socioeconomic characteristics only play a minor role with respect to selection effects in this market.

Overall, our findings provide solid evidence of selection effects in the German SuppDI market even though the coverage-risk correlation is not significantly different from zero. Following Finkelstein and McGarry (2006), we thus argue that more than one type of individual is buying SuppDI coverage: first, individuals with private information about their high risk (adverse selection) and second, low risk individuals who purchase a SuppDI policy because of their preference for insurance (advantageous selection). As suggested by Finkelstein and McGarry (2006) such heterogeneous selection could lead to a market equilibrium that is unlikely to be efficient. Hence, our results indicate that a shifting of dental insurance coverage from public insurance to a private insurance market may suffer from market inefficiencies due to suboptimal insurance coverage by at least some individuals. 
Further research is needed that extends our insights about heterogeneous selection and tests our findings using longitudinal data with better measures for the risk of dental care expenditures and for risk preferences. Such investigation might give more insights into drivers for selection, which explains the remaining significant coverage-risk correlation even after controlling for a comprehensive set of covariates. In addition, it may help to understand better the causal channel by which risk preferences affect the risk of needing health or dental care. Longitudinal data would also allow to examine the lapse behavior and related selection effects with respect to SuppDI coverage. In the meantime, we suggest that insurance companies might gainfully use the selection effects identified here for a more thorough underwriting, which could decrease inefficiencies from information asymmetry. From an insurer's point of view, the selection effects could also be used to better attract low-risk individuals given that the German SuppDI market is not perfectly competitive. 


\section{Appendix}

Table 8 Different Specifications of the Risk Classification on the Relationship of Preference for Insurance with Risk and SuppDI Coverage

\begin{tabular}{|c|c|c|c|c|c|c|}
\hline \multirow[t]{2}{*}{ Dependent Variable } & \multicolumn{3}{|c|}{ Dentist visits >2 } & \multicolumn{3}{|c|}{ SuppDI } \\
\hline & (1) & (2) & (3) & (4) & $(5)$ & (6) \\
\hline \multirow{2}{*}{$\begin{array}{l}\text { Preference for } \\
\text { insurance (continuous) }\end{array}$} & $-0.0204 * *$ & $-0.0142 *$ & $-0.0187 * *$ & $0.2103 * * *$ & $0.2074 * * *$ & $0.1903 * * *$ \\
\hline & $(0.009)$ & $(0.008)$ & $(0.008)$ & $(0.012)$ & $(0.011)$ & $(0.011)$ \\
\hline$X$ full interaction & $\mathrm{x}$ & & & $\mathrm{x}$ & & \\
\hline$X$ no interaction & & $\mathrm{x}$ & & & $\mathrm{x}$ & \\
\hline$X$ linear prediction & & & $\mathrm{x}$ & & & $\mathrm{x}$ \\
\hline $\mathrm{N}$ & 1474 & 1474 & 1474 & 1474 & 1474 & 1474 \\
\hline adj. R2 & 0.160 & 0.135 & 0.224 & 0.217 & 0.210 & 0.265 \\
\hline
\end{tabular}

Notes: Results based on OLS estimates including fear of the dentist \& preventive dentist visits as covariates. Robust standard errors in parentheses. ${ }^{*} \mathrm{p}<.10, * * \mathrm{p}<.05, * * * \mathrm{p}<.01$. 
Table 9 Results of the IV Approach based on Lewbel (2012)

\begin{tabular}{|c|c|c|c|c|c|c|}
\hline \multirow[t]{3}{*}{ Dependent variable } & \multicolumn{2}{|c|}{ Dentist visits >2 } & \multicolumn{2}{|c|}{ No dental issues } & \multicolumn{2}{|c|}{ SuppDI } \\
\hline & (1) & (2) & (3) & (4) & $(6)$ & (5) \\
\hline & OLS & IV & OLS & IV & OLS & IV \\
\hline & \multicolumn{6}{|c|}{ Panel A: Preference for insurance measured as count variable } \\
\hline Preference for & $-0.0210 * *$ & $-0.0269 *$ & $0.0184 * *$ & $0.0361 * *$ & $0.1832 * * *$ & $0.1339 * * *$ \\
\hline & $(0.008)$ & $(0.015)$ & $(0.008)$ & $(0.017)$ & $(0.012)$ & $(0.018)$ \\
\hline $\begin{array}{l}\text { Kleibergen-Paap LM } \\
\text { statistic }\end{array}$ & & 54.295 & & 52.992 & & 60.605 \\
\hline p-value & & 0.0030 & & 0.0042 & & 0.0005 \\
\hline Kleibergen-Paap & & 9.275 & & 7.614 & & 12.548 \\
\hline \multicolumn{7}{|l|}{ Wald F statistic } \\
\hline Hansen J statistic & & 28.981 & & 33.068 & & 46.312 \\
\hline p-value & & 0.4135 & & 0.2332 & & 0.0162 \\
\hline $\begin{array}{l}\text { Breusch-Pagan } \text { Chi }^{2} \\
\text { (First stage) }\end{array}$ & & 173.08 & & 178.09 & & 216.67 \\
\hline \multirow[t]{2}{*}{ p-value } & & 0.0000 & & 0.0000 & & 0.0000 \\
\hline & \multicolumn{6}{|c|}{ Panel B: Preference for insurance measured as binary variable with $1=$ number of SuppHI $>2$} \\
\hline Preference for & $-0.0872 * *$ & $-0.1092 * *$ & $0.0700^{*}$ & 0.0509 & $0.5080 * * *$ & $0.4280 * * *$ \\
\hline & $(0.035)$ & $(0.048)$ & $(0.039)$ & $(0.046)$ & $(0.048)$ & $(0.057)$ \\
\hline $\begin{array}{l}\text { Kleibergen-Paap LM } \\
\text { statistic }\end{array}$ & & 85.163 & & 84.623 & & 86.979 \\
\hline p-value & & 0.0000 & & 0.0000 & & 0.0000 \\
\hline Kleibergen-Paap & & 36.496 & & 48.408 & & 28.095 \\
\hline Wald F statistic & & & & & & \\
\hline Hansen J statistic & & 22.095 & & 35.166 & & 35.213 \\
\hline p-value & & 0.7769 & & 0.1651 & & 0.1637 \\
\hline $\begin{array}{l}\text { Breusch-Pagan } \mathrm{Chi}^{2} \\
\text { (First stage) }\end{array}$ & & 474.69 & & 466.72 & & 603.81 \\
\hline p-value & & 0.0000 & & 0.0000 & & 0.0000 \\
\hline $\mathrm{N}$ & 1392 & 1392 & 1392 & 1392 & 1392 & 1392 \\
\hline
\end{tabular}




\section{Compliance with Ethical Standards}

Funding: We gratefully acknowledge financial support from the Deutscher Verein für Versicherungswissenschaft e.V.

Conflict of interest: Jörg Schiller received research grants from the Deutscher Verein für Versicherungswissenschaft e. V. This research grant was partially used for financing Christopher Schreckenberger. Jan Michael Bauer declares that he has no conflict of interest.

Ethical approval: This article does not contain any studies with human participants or animals performed by any of the authors. 


\section{References}

Angrist JD, Pischke J-S (2009) Mostly harmless econometrics: An empiricist's companion. Princeton Univ. Press, Princeton, NJ

Awaworyi Churchill S, Valenzuela MR, Sablah W (2017a) Ethnic diversity and firm performance: Evidence from China's materials and industrial sectors. Empir Econ 53:1711-1731. doi: 10.1007/s00181-016-1174-5

Awaworyi Churchill S, Appau S, Farrell L (2017b) Religiosity, income and wellbeing in developing countries. Empir Econ. doi: 10.1007/s00181-017-1380-9

Baum CF, Schaffer ME (2012) IVREG2H: Stata module to perform instrumental variables estimation using heteroskedasticity-based instruments, Statistical Software Components S457555, Boston College Department of Economics, revised 18 Feb 2018

Beske F, Drabinski T, Golbach U (2005) Leistungskatalog des Gesundheitswesens im internationalen Vergleich: Eine Analyse von 14 Ländern. Fritz-Beske-Institut für Gesundheits-System-Forschung: Schriftenreihe, 104, I. Schmidt \& Klaunig, Kiel Browne MJ, Zhou-Richter T (2014) Lemons or Cherries?: Asymmetric Information in the German Private Long-term Care Insurance Market. Geneva Pap Risk Insur Issues Pract 39:603-624. doi: 10.1057/gpp.2014.25

Buchmueller TC, Fiebig DG, Jones G, Savage E (2013) Preference heterogeneity and selection in private health insurance: the case of Australia. J Health Econ 32:757-767. doi: 10.1016/j.jhealeco.2013.05.001

Chen M-S, Hunter P (1996) Oral health and quality of life in New Zealand: A social perspective. Soc Sci Med 43:1213-1222. doi: 10.1016/0277-9536(95)00407-6

Chiappori P-A, Salanié B (2013) Asymmetric Information in Insurance Markets: Predictions and Tests. In: Dionne G (ed) Handbook of Insurance, Second edition. Springer, New York, London, pp 397-422 
Chiappori P-A, Durand F, Geoffard P-Y (1998) Moral hazard and the demand for physician services: First lessons from a French natural experiment. Eur Econ Rev 42:499-511. doi: $10.1016 / \mathrm{S} 0014-2921(98) 00015-4$

Chiappori P-A, Salanié B (2000) Testing for Asymmetric Information in Insurance Markets. J Polit Econ 108:56-78. doi: 10.1086/262111

Chiappori P-A, Jullien B, Salanié B, Salanié F (2006) Asymmetric Information in Insurance: General Testable Implications. RAND J Econ 37:783-798. doi: 10.1111/j.17562171.2006.tb00057.x

Cohen A, Siegelman P (2010) Testing for Adverse Selection in Insurance Markets. J Risk Insur 77:39-84. doi: 10.1111/j.1539-6975.2009.01337.x

Cutler DM, Finkelstein A, McGarry K (2008) Preference Heterogeneity and Insurance Markets: Explaining a Puzzle of Insurance. Am Econ Rev 98:157-162. doi: 10.1257/aer.98.2.157 de Meza D, Webb DC (2001) Advantageous Selection in Insurance Markets. RAND J Econ $32: 249-262$

Dionne G (2013) The Empirical Measure of Information Problems with Emphasis on Insurance Fraud and Dynamic Data. In: Dionne G (ed) Handbook of Insurance, Second edition. Springer, New York, London, pp 423-448

Dionne G, Gouriéroux C, Vanasse C (2001) Testing for Evidence of Adverse Selection in the Automobile Insurance Market: A Comment. Journal of Political Economy 109:444-453. doi: $10.1086 / 319557$

Doiron D, Jones G, Savage E (2008) Healthy, wealthy and insured? The role of self-assessed health in the demand for private health insurance. Health Econ 17:317-334. doi: $10.1002 /$ hec. 1267

Ettner SL (1997) Adverse selection and the purchase of Medigap insurance by the elderly. J Health Econ 16:543-562. doi: 10.1016/S0167-6296(97)00011-8 
Fang H, Keane MP, Silverman D (2008) Sources of Advantageous Selection: Evidence from the Medigap Insurance Market. J Polit Econ 116:303-350. doi: 10.1086/587623

Finkelstein A, McGarry K (2006) Multiple Dimensions of Private Information: Evidence from the Long-Term Care Insurance Market. Am Econ Rev 96:938-958. doi: 10.1257/aer.96.4.938

GfK Health Care (2011) Gesundheitsmonitor. Feld- und Methodenbericht - Welle 18 und 19Bevölkerungsbefragung/ Versichertenstichprobe, Nuremberg

Godfried M, Oosterbeek H, van Tulder F (2001) Adverse Selection and the Demand for Supplementary Dental Insurance. De Economist 149:177-190. doi: 10.1023/A:1017566901875

Grabka MM (2014) Zahl privater Zusatzkrankenversicherungen hat sich verdoppelt. DIW Wochenbericht 81:302-307

Grembowski D, Conrad D, Weaver M, Milgrom P (1988) The Structure and Funktion of Dental-Care Markets: A Review and Agenda for Research. Med Care 26:132-147 Hemenway D (1990) Propitious Selection. Q J Econ 105:1063-1069. doi: 10.2307/2937886 Hofmann A, Browne M (2013) One-sided commitment in dynamic insurance contracts: Evidence from private health insurance in Germany. J Risk Uncertain 46:81-112. doi: $10.1007 / \mathrm{s} 11166-012-9160-6$

Holly A, Gardiol L, Domenighetti G, Bisig B (1998) An econometric model of health care utilization and health insurance in Switzerland. Eur Econ Rev 42:513-522. doi: $10.1016 / \mathrm{S} 0014-2921(98) 00003-8$

Keane M, Stavrunova O (2016) Adverse selection, moral hazard and the demand for Medigap insurance. J Econom 190:62-78. doi: 10.1016/j.jeconom.2015.08.002 
Kiil A (2012) What characterises the privately insured in universal health care systems? A review of the empirical evidence. Health Policy 106:60-75. doi: 10.1016/j.healthpol.2012.02.019

Klingenberger D, Micheelis W (2005) Befundbezogene Festzuschüsse als innovatives Steuerungsinstrument in der Zahnmedizin: Systemtheoretische Einordnung und empirische Befunde. IDZ-Forschungsbericht, Cologne

Lahiri K, Xing G (2003) Modeling Medicare-Eligible Veterans' Demand for Outpatient Services: A Two-Stage Approach. Health Serv Outcomes Res Method 4:221-240. doi: $10.1007 / \mathrm{s} 10742-005-5558-9$

Lang WP, Farghaly MM, Ronis DL (1994) The relation of preventive dental behaviors to periodontal health status. J Clin Periodontol 21:194-198. doi: 10.1111/j.1600051X.1994.tb00303.x

Lange R, Schiller J, Steinorth P (2017) Demand and Selection Effects in Supplemental Health Insurance in Germany. Geneva Pap Risk Insur Issues Pract 42:5-30. doi: 10.1057/s41288016-0023-2

Le Moglie M, Mencarini L, Rapallini C (2015) Is it just a matter of personality? On the role of subjective well-being in childbearing behavior. Journal of Economic Behavior \& Organization 117:453-475. doi: 10.1016/j.jebo.2015.07.006

Levin L, Shenkman A (2004) The Relationship Between Dental Caries Status and Oral Health Attitudes and Behavior in Young Israeli Adults. J Dent Educ 68:1185-1191

Lewbel A (2012) Using Heteroscedasticity to Identify and Estimate Mismeasured and Endogenous Regressor Models. Journal of Business \& Economic Statistics 30:67-80. doi: $10.1080 / 07350015.2012 .643126$ 
Lewbel A (2018) Identification and estimation using heteroscedasticity without instruments:

The binary endogenous regressor case. Economics Letters 165:10-12. doi:

10.1016/j.econlet.2018.01.003

Lin F, Weldemicael EO, Wang X (2017) Export sophistication increases income in sub-Saharan Africa: Evidence from 1981-2000. Empir Econ 52:1627-1649. doi: 10.1007/s00181-016$1103-7$

Manning WG, Bailit HL, Benjamin B, Newhouse JP (1986) The Demand for Dental Care: Evidence from a Randomized Trial in Health Insurance. The RAND Corporation, Santa Monica, CA

Manning WG, Newhouse JP, Duan N, Keeler EB, Leibowitz A (1987) Health Insurance and the Demand for Medical Care: Evidence from a Randomized Experiment. Am Econ Rev $77: 251-277$

Meyerhoefer CD, Zuvekas SH, Manski R (2014) The demand for preventive and restorative dental services. Health Econ 23:14-32. doi: 10.1002/hec.2899

Mueller CD, Monheit AC (1988) Insurance coverage and the demand for dental care. J Health Econ 7:59-72. doi: 10.1016/0167-6296(88)90005-7

Nyman JA (1999) The value of health insurance: The access motive. J Health Econ 18:141152. doi: 10.1016/S0167-6296(98)00049-6

OECD (2013) Health at a Glance 2013: OECD Indicators, OECD Publishing. http://dx.doi.org/10.1787/health_glance-2013-en

Paccagnella O, Rebba V, Weber G (2013) Voluntary private health insurance among the over 50s in Europe. Health Econ 22:289-315. doi: 10.1002/hec.2800

Paris V, Devaux M, Wei L (2010) Health Systems Institutional Characteristics: A Survey of 29 OECD Countries, OECD Health Working Papers, No. 50, OECD Publishing, Paris. http://dx.doi.org/10.1787/5kmfxfq9qbnr-en 
Pauly MV (1968) The Economics of Moral Hazard: Comment. Am Econ Rev 58:531-537

Pauly MV, Kunreuther H, Hirth R (1995) Guaranteed renewability in insurance. J Risk Uncertainty 10:143-156. doi: 10.1007/BF01083557

Petersen PE (2003) The World Oral Health Report 2003: Continuous improvement of oral health in the 21st century - the approach of the WHO Global Oral Health Programme. Commun Dent Oral Epidemiol 31:3-24. doi: 10.1046/j.2003.com122.x

Rädel M, Hartmann A, Bohm S, Walter M (2014) BARMER GEK Zahnreport 2014: Auswertungen von Daten des Jahres 2012 mit Schwerpunkt Wurzelbehandlung. Schriftenreihe zur Gesundheitsanalyse, Band 25. Asgard Verlagsservice, Siegburg

Rothschild M, Stiglitz J (1976) Equilibrium in Competitive Insurance Markets: An Essay on the Economics of Imperfect Information. Q J Econ 90:629-649

Schmitz H (2011) Direct evidence of risk aversion as a source of advantageous selection in health insurance. Econ Lett 113:180-182. doi: 10.1016/j.econlet.2011.06.016

Shavell S (1979) On Moral Hazard and Insurance. Q J Econ 93:541-562

Srivastava P, Chen G, Harris A (2017) Oral Health, Dental Insurance and Dental Service use in Australia. Health Econ 26:35-53. doi: 10.1002/hec.3272 